\title{
Evaluation of Space-Time Pattern on Haze Polluttion and Associated Health Losses in the Yangtze River Delta of China
}

\author{
Haixia Zhao*, Shufen Wang \\ ${ }^{1}$ Key Laboratory of Watershed Geographic Sciences, Nanjing Institute of Geography and Limnology, \\ Chinese Academy of Sciences, Nanjing 210008, China
}

Received:2 December 2016

Accepted: 16 January 2017

\begin{abstract}
Haze has become an important topic for discussion in relation to global atmospheric pollution prevention and control due to its environmental and health effects. In order to explore the change in the space-time pattern of haze in the Yangtze River Delta of China and the associated human health losses, this paper uses MODIS Level 2 aerosol products of 2000-14 as well as applying the Kriging interpolation method to analyze the characteristics of changes of aerosol optical depth (AOD). The human capital method is then applied to evaluate the health losses caused by haze pollution in 2004-13. The research proves that in the latest 15 years, the AOD in the Yangtze River Delta has fluctuately risen from 0.5645 in 2000 to 0.5841 in 2014, with the spatial distribution pattern higher in the north and lower in the south. The northern cities of Shanghai, the southern part of Jiangsu Province, and the Hangzhou Bay region have always registered highest values. This analysis also shows that elevated concentration has gradually spread toward the southern areas. Meanwhile, the health losses in the whole region and each city have tended to be aggravated; the health losses in southern cities are far lower than those in northern cities. For example, the southern cities of Zhoushan and Taizhou see the lowest health losses ( $\$ 0.039$ billion and $\$ 0.035$ billion, respectively). Conversely, the highest health losses are located in the northern cities of Shanghai, at $\$ 13.60$ billion. However, the growth rate of health losses in southern cities is obviously higher than that in northern cities as a result of pollution transfer at the average rates of $249.18 \%$ and $99.94 \%$.
\end{abstract}

Keywords: haze pollution, health losses, aerosol optical depth (AOD)

\section{Introduction}

Haze is traditionally an atmospheric phenomenon where dust, smoke, and other dry particles obscure the clarity of the sky (en.wikipedia.org/wiki/Haze). Haze pollution is one of the more noticeable environment

*e-mail: hxzhao@niglas.ac.cn outcomes in the process of China's rapid industrialization and urbanization [1-4]. $\mathrm{PM}_{2.5}$, the aerodynamic equivalent diameter not larger than $2.5 \mu \mathrm{m}$, has been regarded as the core pollutant of haze formation [5]. Because the composition of the aerosols forming haze are complex and heterogeneous, it is difficult to assess and there is a lack of consistent time series data. However, AOD, as an important physical quantity for measuring atmospheric turbidity, can be used as a proxy indicator of haze and quantify 
the space-time changes in hazy weather [6]. Industries, power plants, traffic, and biomass burning are the main sources of haze primary pollutants, including particle and trace gases [7-8]. For these reasons, deterioration of the phenomenon has been continued, characterized by high pollution, excessive energy consumption, and tremendous emissions. Meanwhile, factors such as a dramatic increase of air pollution, ubiquitous construction site dust, and insufficient pollution controls have led to the fact that the total emissions of air pollutants far exceed environmental capacity. Haze is a constant presence in some largeand medium-sized cities, especially in some economic concentration regions such as the Yangtze River Delta, the Beijing-Tianjin-Hebei region, and the Pearl River Delta [9-10]. In these most-developed areas haze has been the primary air pollutant, and has had obvious negative effects upon the climate, health, economy, etc. [11-12]. The Yangtze River Delta is a leading center for economic development in eastern China and the region with the most concentrated manufacturing industry in China. Here, air pollution is extremely serious: haze days appear repeatedly, on average more than 100 days annually and especially more than 200 days in some cities [13-14]. This significantly affects agricultural production, quality of life, and residents' health, and has aroused the attention of the public and the authorities' [11].

At present, both domestic and overseas research focuses mainly on the space-time characteristics of events and their change over time, health effects, and countermeasures for the control of haze. Xu et al. [15], Tong et al. [16], Fan et al. [17], Gao [18], and others have analyzed the space-time characteristics of haze in typical cities using techniques such as remote sensing data and site monitoring. Yang et al. [19] further evaluated the influences of haze on human health, and on this basis some formed a relatively systematic health effect evaluation method [20-23]. Matus et al. discovered in their research on health effects of air pollution in China that the sum of the same two disorders accounted for $90 \%$ of total casualties [24]. The composition of haze is complex, so scholars have researched the changes in haze by researching its aerosol optical characteristics [25-27]. This information has been used to develop improved countermeasures for warning and control [28], and has provided important references for further investigation [29]. Air pollution has become the world's largest single environmental health risk, especially in urban agglomerations [20]. All of this means that it is necessary to analyze the relationship of haze and health. Research focusing on specific cities has been ongoing for some time, but there is little evidence of patterns and health outcomes on a regional scale [28]. Some scholars have developed research on the haze in the Pearl River Delta City Group, but there is little research related to the east Yangtze River Delta with its developed economy and dense population.

This paper aims to fill this gap by analyzing the spacetime characteristics of haze over time and evaluating the associated health losses in the past decade. Therefore, this study investigazed (a) the time seguence change, spatial distribution patterns, and spatial change characteristics of AOD from 2005 to 2014, and (b) the relationship of health losses and AOD in 16 cities on the Yangtze River Delta. This research can provide a theoretical basis for further research on haze pollution, as well as providing the basis for improving air quality management in China. In addition, it can also improve the understanding of the relationship between haze pollution and human health, and help to prevent global health disease caused by air pollution during urban expansion and economic growth.

\section{Overview of Research Area}

The Yangtze River Delta is formed from the alluvial deposits of the Yangtze and Qiantang rivers where they enter the sea. It is the intersection point of the east coast open city belt with a strip of densely-populated industrialized cities along the banks of the Yangtze River. According to the Regional Planning Department of the Yangtze River Delta this includes 16 cities: Shanghai, Nanjing, Yangzhou, Zhenjiang, Taizhou, Nantong, Suzhou, Wuxi, Changzhou, Hangzhou, Shaoxing, Huzhou, Jiaxing, Ningbo, Zhoushan, and Taizhou (Fig. 1). As the region with the highest urbanization and industrialization levels, the densest population, and the highest rate of land development in China, the Yangtze River Delta accounted for $20.8 \%$ of regional GDP ( $\$ 8.594$ thousand billion), $2.2 \%$ of national land area $\left(9.6\right.$ million $\left.\mathrm{km}^{2}\right)$,

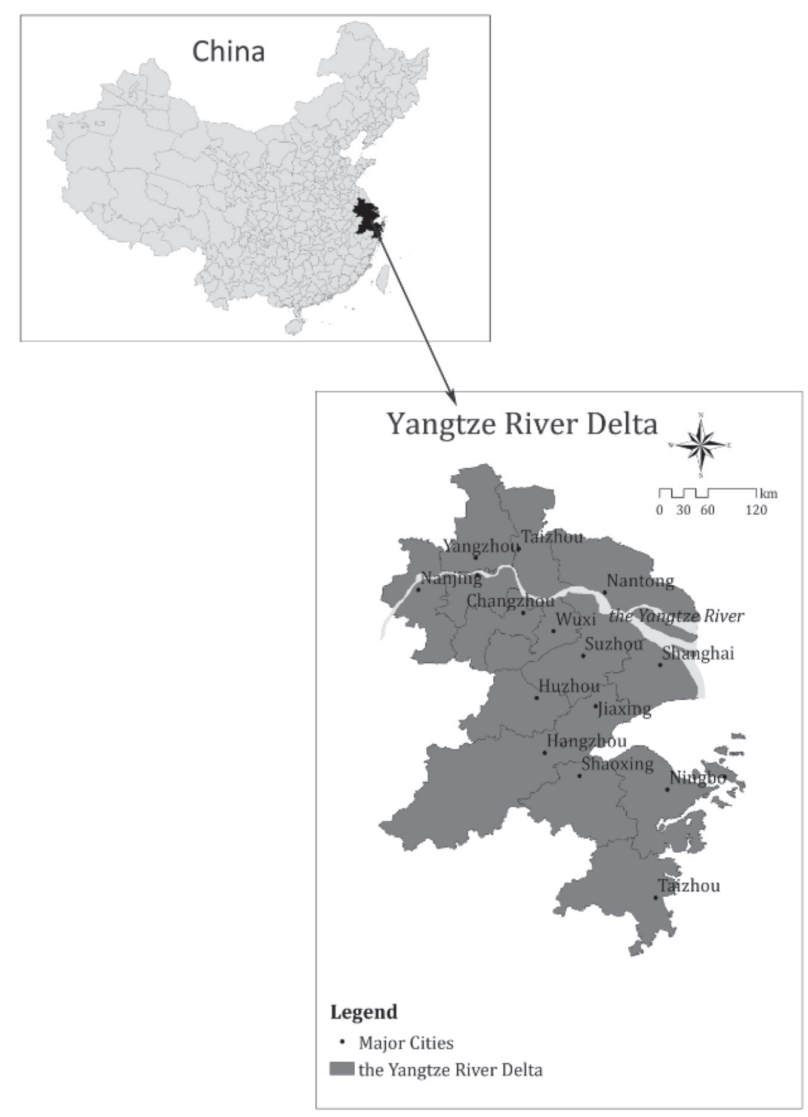

Fig. 1. Location of the study area. 
and $11.7 \%$ of the population ( 1.361 billion) at the end of 2013. However, along with rapid economic development, the Yangtze River Delta has suffered increasingly severe environmental pollution, and the discharge of pollutants per unit area here is more than five times that in other regions in China [25]. Haze is the primary pollutant in the Yangtze River Delta with annual concentration of $\mathrm{PM}_{2.5}$ $67 \mu \mathrm{g} / \mathrm{m}^{3}$ in 2013 [29], while the Chinese government upgraded the national ambient air quality standard to annual limit of $35 \mu \mathrm{g} / \mathrm{m}^{3}$ in 2012 (GB3095-2012) [30]. The Yangtze River Delta has become the region with the quickest growth of pollution discharge in China, which has produced a range of extremely marked consequences for regional economic development, ecology, and climate.

\section{Material and Methods}

\section{MODIS Data and Treatment}

MODIS provides high resolution aerosol products and provides a new means for researching regional environmental air pollution. At present, it is generally accepted as the most effective data for space monitoring of aerosol characteristics, and provides information through 36 channels of $0.145-14.235 \mu \mathrm{m}$. The sensor covers the whole world once every day, with a scanning width of 2,330 km and resolutions of $250 \mathrm{~m}$ ( 2 channels), $500 \mathrm{~m}$ ( 5 channels), and 1,000 m (29 channels). It provides abundant data for thorough research of terrestrial, oceanic, and atmospheric characteristics. A comparative analysis of ground observation and satellite remote sensing data by Liu et al. [14] and Mao et al. [31] demonstrated that MODIS aerosol analysis has sufficient quality and precision to be applied to researching aerosol optical characteristics. Hence this paper adopts the MODIS Terra Atmosphere Level 2 products data issued by NASA, specifically product level MOD04, wave band 550nm, resolution rate $1 * 1$, timescale $2005-14$, and scope $28.75^{\prime} \mathrm{N}-33.31$ ' $\mathrm{N}$, 118.33 'E-123.31'E. The data are analyzed mainly through Matlab and processed by the Kriging interpolation method.

\section{The Kriging Interpolation Method}

In statistics, originally in geostatistics, Kriging process regression is a method of interpolation for which the interpolated values are modeled by a Gaussian process governed by prior covariances, as opposed to a piecewisepolynomial spline chosen to optimize smoothness of the fitted values (wikipedia.org/wiki/Kriging\#Methods). Based on other criteria such as smoothness need not yielding the most likely intermediate values, the Kriging interpolation method is widely used in the domain of spatial analysis and computer experiments. Under suitable assumptions on the priors, Kriging gives the best linear unbiased prediction of the intermediate values. It is able to calculate the size of the error of each estimated value so that it can know the reliability of the estimated value. Therefore, this paper uses the Kriging interpolation method to estimate the value of aerosol optical depth at unobserved locations.

$$
\mathrm{Z}\left(x_{0}\right)=\left[w_{1} w_{2} \cdots w_{n}\right] \cdot\left[\begin{array}{c}
z_{1} \\
z_{2} \\
\vdots \\
z_{n}
\end{array}\right]=\sum_{i=1}^{n} w_{i}\left(x_{0}\right) \times \mathbf{Z}\left(x_{i}\right)
$$

... where $Z\left(x_{0}\right)$ is the kriged or predicted value, $Z_{i}=Z\left(x_{i}\right)$ is the observed value, $w_{i}=w_{i}\left(x_{\theta}\right)$ is the weights at an unobserved location $x_{0}$, and $I=1, \ldots, N$.

\section{Human Capital Method for Evaluating Health Losses}

Haze pollution, an international issue caused by aerosols, has brought about heavy smog pollution events like London smog and Los Angeles smog. When haze occurs, the concentration of fine particles in the air increases sharply and forms secondary aerosols [5]. The optical properties and moisture absorption of aerosols have significant effects on visibility, and the toxic ingredients carried by the aerosol bring about threats to human health [32]. Now it has drawn great attention because of its adverse effects on climate, air quality, and human health [30]. The influences of haze pollution on human health are very complicated and its functional mechanisms are still not clear, but plentiful epidemiological research shows that a hazy day is closely related to various health conditions [33]. The existing research proves that the greatest threats from pollution are premature death and chronic bronchitis [34]. For example, Ostro and Chestnut (1998) discovered in their research on the consequences of air pollution in the USA that death and chronic bronchitis were $82 \%$ and $12 \%$ of total losses, respectively. In this paper, we treat premature death as the health effect criterion and construct a dose-response relationship function to calculate the population of premature deaths, then estimate the economic losses arising from the health effects of haze by monetizing the health losses according to the human capital method, as shown below:

$$
\begin{gathered}
E=p o p \cdot M \cdot \beta \cdot\left(c-c_{0}\right) \\
L=E \cdot L_{p}
\end{gathered}
$$

...where $E$ indicates the health effect variation of the health criterion, namely the premature death toll; $p o p$ indicates the exposed population; $M$ indicates the baseline of the health effect criterion, namely the mortality rate; $\beta$ is the dose response relationship coefficient, indicating the relationship coefficient between the changing health risk and the changing value of $\mathrm{AOD} ; c_{0}$ is a benchmark 
zero-limit value; $c$ indicates the AOD baseline value; $L$ indicates the economic losses due to health effects; $E$ indicates the premature death toll; and $L_{P}$ indicates the economic losses due to health effects quantified according to per capita GDP.

The coefficient of the dose response relationship is calculated according to the relationship coefficient between the health effect terminal risk and $\mathrm{PM}_{25}$ change [34], and the relationship between $\mathrm{PM}_{2.5}$ and AOD [36]. In this paper, it is determined to be 0.000675 according to the research of Huang et al. [10]. At the same time, due to different geographic and meteorological conditions, there are substantial differences in the number of people of different social strata exposed to high pollutant concentrations, so there is a certain difficulty to determining the exposed population in a certain region. Generally, air pollution is closely related to industrialization and urbanization; urban residents are the main victims of outdoor air pollution. Therefore, the exposed population considered in evaluation of health losses just includes urban permanent residents only.

\section{Data Sources}

The population and economic data used are mainly the permanent urban resident population, per capita GDP, and mortality rate in the study area. We drew data from the statistical yearbooks of Jiangsu Province, Zhejiang Province, and Shanghai city, as well as statistical yearbooks of 16 cities in the Yangtze River Delta from 2005 to 2014. The economic data are subject to constant price indexing on the basis of 2004.

\section{Results and Discussion}

\section{Space-Time Change Characteristics of AOD}

The daily average value of AOD in December 2013 was significantly high, and there existed a similar trend between the AOD value and $\mathrm{PM}_{2.5}$ concentrations (Fig. 2). The daily AOD value rose from 0.6 on December 2 and reached a peak value of 2.2 on December 6 , and then fluctuated before falling to 0.4 on December 12. At the same time the Yangtze River Delta suffered a heavy haze pollution event with daily concentrations of $\mathrm{PM}_{2.5}$ and more than $150 \mu \mathrm{g} / \mathrm{m}^{3}$ and rose constantly before December 6, while it dropped quickly from December 7 to 12 , and the hazy weather weakened and was dissipated due to a southward movement of cold air and a large-area temperature drop. It was reported that there is significant positive correlation between the concentration of $\mathrm{PM}_{2.5}$ and the value of AOD at the 0.01 level by Pearson correlation analysis, with the coefficient reaching 0.763 and the changes of both AOD and hazy concentrations tending to be strongly correlated. These results are also consistent with the research findings of Mao et al. [30]. This further justifies the use of the MODIS AOD data as an indicator of space-time patterns on haze over the region.

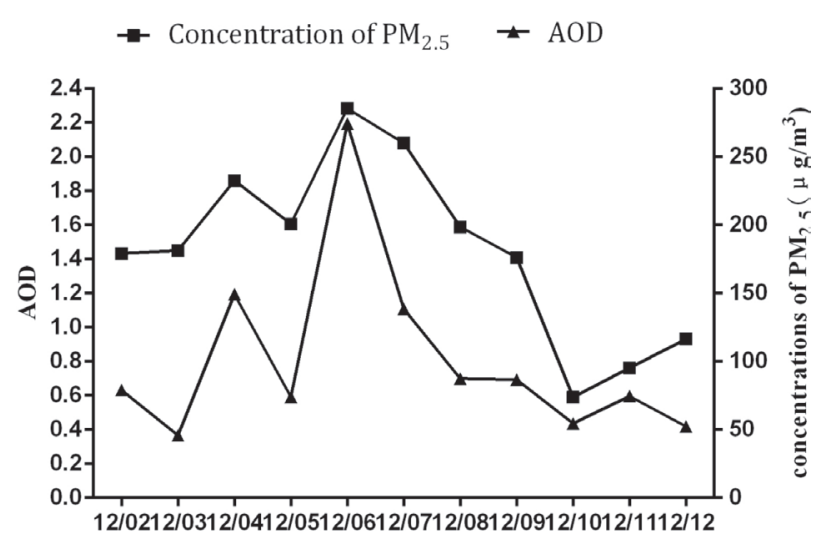

Fig. 2. Daily AOD values and concentrations of $\mathrm{PM}_{2.5}$ December 2-12, 2013.

\section{Time Sequence Change}

Between 2000 and 2014 the annual average value of AOD in the Yangtze River Delta showed a fluctuating but rising trend (Fig. 3). The 2000-07 period was associated with a noticeable increase, and the annual average value rose from 0.5645 in 2000 to 0.6698 in 2007, reaching its peak value when the air pollution was particularly severe. Between 2007 and 2014 there was a period of decline. The annual average value was 0.5841 in 2014 , a drop of $10.61 \%$, and this was in large part a result of the emission control measures adopted by the government in preparation for international sporting contests such as the World Expo and the Youth Olympic Games [13]. The time sequence change of a haze day was governed by factors such as regional weather conditions, land use, population, and air pollutant discharge levels [37]. Fast industrialization and urbanization, as well as dramatic increases in construction land, brought about a sharp decrease in farm and forest land areas, etc., reduced atmospheric humidity, and produced more frequent haze. Meanwhile, along with increases in regional population and industrial enterprises, the appearance of high rises and high-density building clusters has weakened regional wind flows and resulted

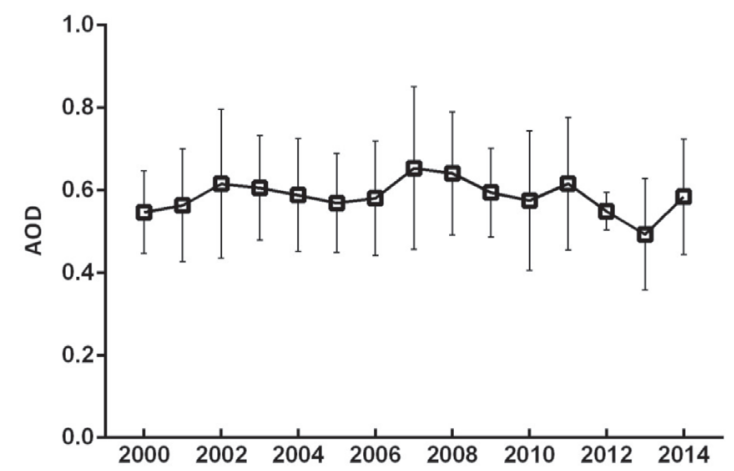

Fig. 3. Annual average value of AOD in the entire region, 2000-14. 
in a higher frequency and intensity of haze events in the region. In addition, increased consumption of fossil fuel energy resources as well as a rapid increase in motor vehicle ownership have inevitably led to increases in automobile exhaust gas and pollutant emissions, in addition to floating particles in the air, thus causing "secondary pollution" and expanding the scale and effects of haze.

\section{Spatial Characteristics}

\section{Spatial distribution patterns}

The Yangtze River Delta had always been a high value area in terms of $A O D$, with a spatial distribution pattern of "high in the north and low in the south" (Fig. 4). From 2000 to 2014 the average value of AOD increased from 0.59 to 0.71 in the north, and from 0.35 to 0.42 in the south. This is due to the influences of geography and development factors through differences in the special characteristics of terrain, population density, industrial layout, vegetation coverage, etc. The northern plain has lower terrain, mostly covered with farmland, towns and cities, water bodies, etc. It has a high population density, dense urban industrial areas, intensive human and industrial activity, and high pollution discharge levels, so the values of AOD here are relatively high - especially in areas surrounding Shanghai, where they reached 1.2 in
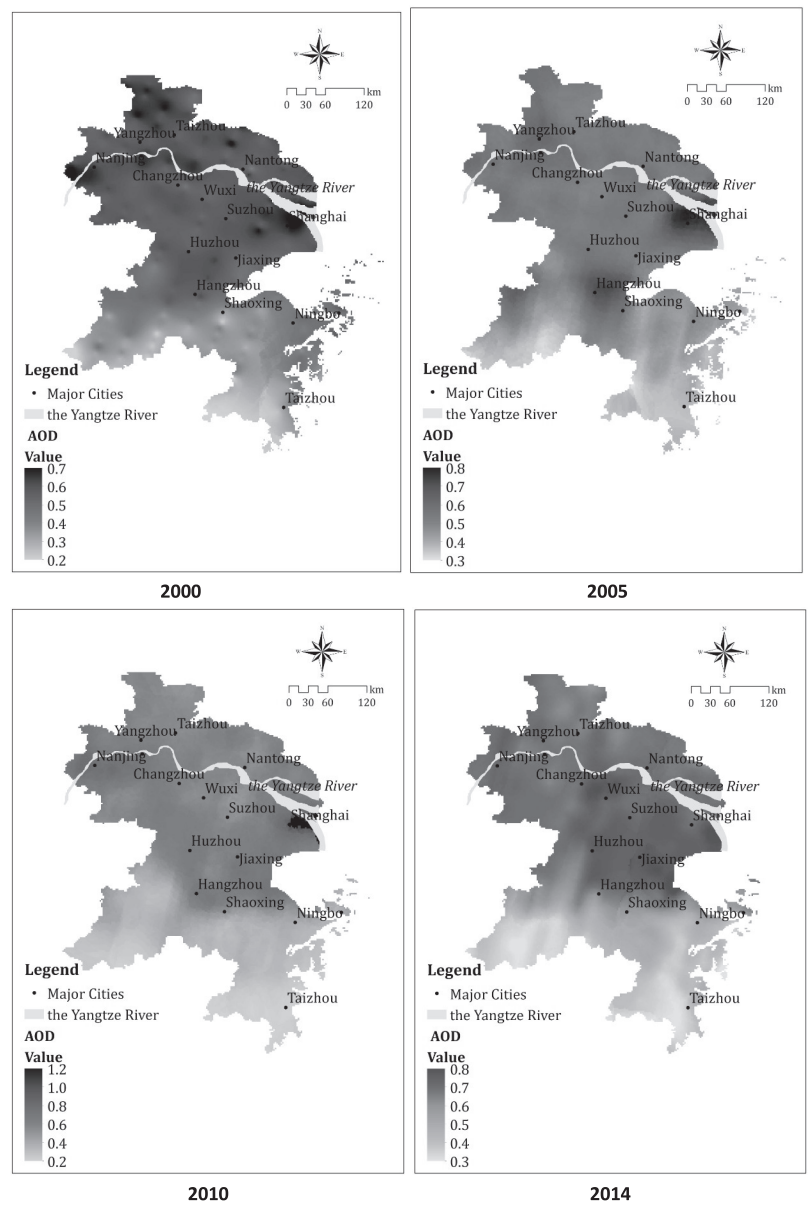

Fig. 4. Spatial distribution patterns of AOD value in 2000-14.
2013. For example, in Shanghai, one of the most important urban areas in China, the annual average concentration of $\mathrm{PM}_{2.5}$ was around $62 \mu \mathrm{g} / \mathrm{m}^{3}$ in 2013 [38], and there were 445 haze days from 2008 to 2010 , accounting for $41 \%$ of all natural days [39]. On the other hand, the southern areas are mostly mountainous, with the land surface covered mainly with forest and grassland. The vegetation coverage is good, serving to reduce the release of wind-borne particles into the atmosphere and encourage deposition. Moreover, there is little impact from industrial activity, so the AOD has a relatively low value of 0.57 . The areas, along the banks of the Yangtze River and the coastal belts with dense industrial zones have acquired high values of AOD. It is implied that urbanization and industrialization are important reasons behind the dramatic increase in AOD.

2. Spatial change characteristics

In 2000-14 the northern metropolitan areas such as Shanghai, Nanjing, and Hangzhou were always the areas with highest AOD values. These are deeply affected by population growth and urban expansion. These high AOD value areas have been constantly enlarged, expanding to the northeast and south. In 2010, the areas with AOD values over 0.6 were more than $60 \%$ of the region, while those of greater than 0.8 increased rapidly and expanded constantly. Before 2005, the high AOD value areas were mainly south of Jiangsu, Shanghai, and some cities around Hangzhou Bay. Along with the constant diffusion of air pollutants, the high AOD value areas merged in 2014, showing strong evidence of regional pollution and a powerful case for increased governance, prevention, and control.

AOD in the cities of the Yangtze River Delta have demonstrated a growing trend over the past 15 years, but the growth rates differ markedly. In southwestern Hangzhou and the southern cities of Shaoxing, Ningbo, and Taizhou, the AOD value has grown year after year, but due to high vegetation coverage and low population density, the growth rate has been negligible, with AOD values always lower than 0.5 . In response to the implementation of measures to adjust industrial processes and reduce emissions, the AOD values of southern cities except for Nanjing of Jiangsu Province have seen rising trends halted and an improvement of haze-related air quality of levels around 0.7. Shanghai, as an international metropolis, has high population density, rapid expansion of construction lands, and large-scale discharge of air pollutants, and its AOD value of 0.86 is the highest in the Yangtze River Delta. In the Hangzhou Bay areas of Ningbo, Shaoxing, and Jiaxing, as well as the northeastern areas of Hangzhou, the discharge rate of air pollutants is high, with AOD values rising year after year to reach around 0.6, and the high AOD value areas expanding constantly.

\section{Health Loss Evaluation}

In 2004-13, the estimated health losses in the Yangtze River Delta added $\$ 0.18$ billion (an increase of $49.2 \%$ ). 


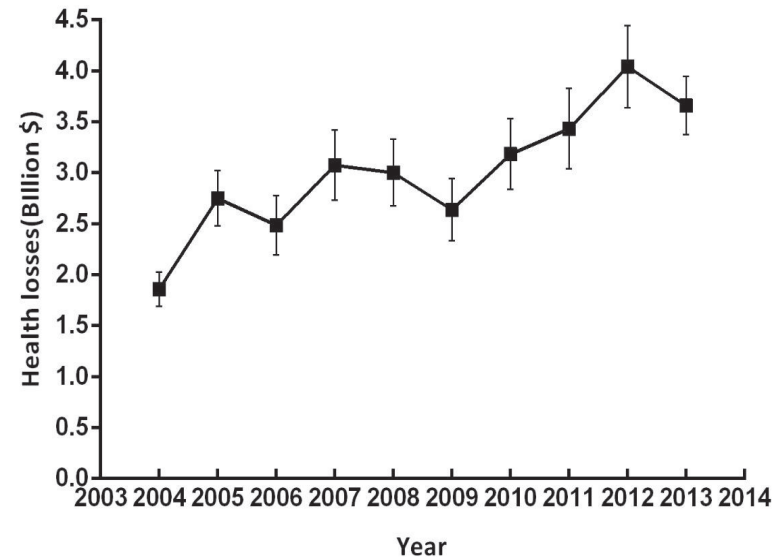

Fig. 5. Health losses induced by haze in 2004-13 across the entire area.

This is equivalent to rising from $\$ 1.86$ billion in 2004 to $\$ 3.66$ billion in 2013 . The period 2004-09 was a slow growth stage, and the economic loss of the whole region grew slowly by only $\$ 0.78$ billion. The period 2009-13 was the fastest growth stage, and especially in 2009-12, the economic losses presented a similarly linear growth with values increasing from $\$ 2.64$ billion to a maximum of $\$ 4.04$ billion (Fig. 5). Obviously affected by regional meteorological conditions, land use intensity, economic development, urbanization, population growth, and pollutant discharge, the health losses arising from haze in the Yangtze River Delta were seen to be consistent with the spatiotemporal patterns in haze.

Along with economic development, population movements, and health effects lagging, the healthy losses induced by haze in each city have presented an increasing trend and the range of change is different (Fig. 6 and Table 1). Besides, the health losses in the northern cities are obviously higher than those in the southern cities. For example, the northern cities, such as Shanghai, Suzhou, Wuxi, Nanjing, and Hangzhou have

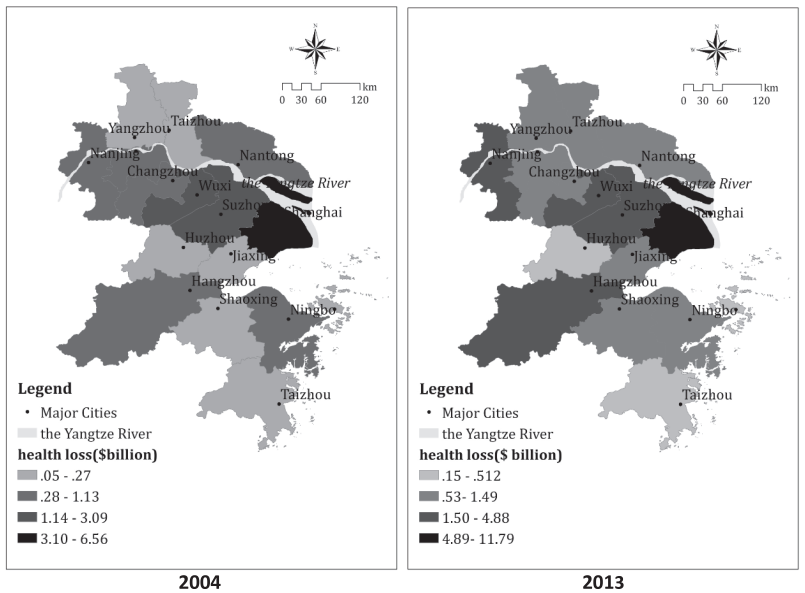

Fig. 6. Spatial distributions of health losses induced by haze in 2004 and 2013
Table 1 . Health losses and the growth rate of every city in 2004 and 2013.

\begin{tabular}{|c|c|c|c|}
\hline Cities & $\begin{array}{c}2004 \\
\text { (billion \$) }\end{array}$ & $\begin{array}{c}2013 \\
\text { (billion \$) }\end{array}$ & $\begin{array}{c}\text { Growth rate } \\
(\%)\end{array}$ \\
\hline Shanghai & 6.56 & 11.79 & 79.76 \\
\hline Nanjing & 1.13 & 2.44 & 115.51 \\
\hline Nantong & 0.81 & 1.08 & 32.30 \\
\hline Suzhou & 3.09 & 4.88 & 57.99 \\
\hline Wuxi & 2.11 & 2.99 & 41.89 \\
\hline Zhoushan & 0.05 & 0.15 & 204.99 \\
\hline Ningbo & 0.63 & 1.49 & 137.39 \\
\hline Hangzhou & 1.08 & 2.57 & 138.52 \\
\hline Changzhou & 0.86 & 1.42 & 65.32 \\
\hline Taizhou & 0.25 & 0.91 & 261.39 \\
\hline Zhenjiang & 0.75 & 0.93 & 23.95 \\
\hline Yangzhou & 0.27 & 0.88 & 221.45 \\
\hline Huzhou & 0.12 & 0.36 & 191.99 \\
\hline Shaoxing & 0.20 & 0.95 & 373.75 \\
\hline Jiaxing & 0.17 & 0.78 & 346.49 \\
\hline Taizhou & 0.11 & 0.52 & 351.13 \\
\hline
\end{tabular}

suffered the most severe health losses at $\$ 13.60$ billion, $\$ 5.01$ billion, $\$ 3.14$ billion, $\$ 2.29$ billion, and $\$ 2.08$ billion in 2013. Conversely, southern cities such as Taizhou and Zhoushan have relatively weak haze pollution and the lowest health losses, at values of $\$ 0.04$ billion and $\$ 0.036$ billion. Due to the southward movement of gravity, the center of industrial pollution in the Yangtze River Delta in recent years [20] and the southern cities especially Shaoxing, Jiaxing, and Zhoushan - have seen a greater increase in health losses at $373.75 \%, 351.13 \%$, and $346.49 \%$, respectively, while the northern cities such as Zhenjiang and Nanjing have seen relatively lower increase at $23.95 \%$ and $32.30 \%$ in the period $2004-13$.

\section{Discussions}

Based on the MODIS product, this paper inverts the space-time change of AOD in 2000-14. Additionally, by using the dose-response relationship formula and the human capital method, it evaluates the health losses attributable to haze in 2004-13. In the Yangtze River Delta, it was found that AOD presented a growing trend as high AOD value areas increased significantly and expanded gradually southward. This is consistent with the conclusions of Zhai et al. [13]. While the results of health losses are slightly higher than those of other related research projects for cities within the region. For example, we found the health losses of Shanghai in 2013 were up to $\$ 1.20$ billion - four times more than shown in research by 
Mu et al. [40]. These results are due to the improvement of methods. First and foremost, this paper further subdivided the aerosol model according to the long-term data actually measured on the ground, and explored more accurate inversion methods according to specific ground surface conditions. However, because the AOD value inversion based on dark target method in some research deviates from the actual value, when AOD is relatively smaller, the inversion result will tend to be smaller. Additionally, it is obvious that much uncertainty exists in the evaluation of health losses, because the characteristics of aerosol and the types of underlying surface in the study regions are highly complex. Simultaneously, factors such as inconsistency of health outcomes, diversity of evaluation methods, and uncertainty of parameters may play an important role in discrepancies between research data.

1. Inconsistency of health effects. The influences of atmospheric pollution on human health are categorized as acute effects and chronic effects [41]. Acute effects occur over a short period, for example if a high concentration haze event causes a paroxysm of acute respiratory tract diseases and chronic cardiocerebrovascular diseases and premature deaths [42]; while chronic diseases such as chronic bronchitis persist over long periods as a result of long-term exposure to pollution. The economic losses arising from premature death and chronic bronchitis account for $80-90 \%$ of total losses, while the health losses related to emergency treatment/outpatient services account for only $9 \%$ of total health losses. Restricted by factors such as data availability, this paper only calculated the losses arising from premature death, so the research result is lower than the actual health losses, which in practice will include premature death and chronic bronchitis.

2. Diversity of evaluation methods. The methods in common use for health loss evaluation include the disease cost method, the human capital method, and the willingness to pay method [10]. The three methods are applicable to the evaluation of economic losses according to different health effects. The disease cost method includes all the direct expense and indirect expense related to the diseases during the period when patients suffer diseases, but excludes the mental losses brought about by diseases. The calculation result is only a conservatively estimated lower limit of total losses, so it is applicable to non-fatal diseases or acute diseases. The willingness-to-pay method takes individuals' willingness to pay for raising their own health standard as economic losses, and at present there is little research in China for evaluating the economic losses due to health using this method. The human capital method is mainly applicable to the evaluation of economic losses arising from premature death, and takes the difference in social contribution caused by sickness or death as the economic losses caused by the effects of environmental pollution on human health. Therefore, this research takes premature death as the health effect and uses the human capital method to evaluate health-related economic losses, but the result is lower. Subsequent research might consider the influences of different health effects and evaluation methods.

3. Uncertainty of parameters. At present, there is no unique average standard value of AOD, and only zero is taken as a benchmark concentration value, although in fact there is always a background value and so zero is unrealistic. In addition, the relationship coefficient between changes in health risk and changes in the AOD value is calculated through the relationship coefficient between changes in health risk and changes in $\mathrm{PM}_{2.5}$, as well as the relationship between $\mathrm{PM}_{2.5}$ and AOD in existing research; this represents a slight deviation from the actual situation, and should be subject to further empirical research.

\section{Conclusions}

1. In this paper, we report new health loss results based on improved estimates of aerosol optical depth for the Yangtze River Delta of China. We have accurately inverted the space-time changes of AOD, subdivided the aerosol model according to long-term data actually measured on the ground, and explored more accurate inversion methods according to specific ground surface conditions as well as applying the Kriging interpolation method to analyze the changes of AOD. In the Yangtze River Delta, AOD was found to have a fluctuating increase in the period 2000-14. The spatial distribution patterns revealed are due to factors such as meteorological conditions, land use, regional urbanization, and atmospheric pollutant discharge. The AOD of each city rose year after year, and the range of change was different, but the high-value areas were highest in Shanghai, south of Jiangsu Province and Hangzhou, and gradually expanded to large areas in the southern areas.

2. Due to the complexity of characteristics, there is some uncertainty derived from three main sources: inconsistency of health outcomes, diversity of evaluation methods, and uncertainty of parameters. However, in order to understand health losses in the region, this paper represented a contribution by applying new techniques: the dose-response relationship formula and the human capital method. The estimated health losses induced by haze in the Yangtze River Delta had an increase of $49.2 \%$ from 2004 to 2013. Moreover, it was revealed that the spatial patterns of health losses were the same as for the AOD value. On the whole, the value of losses in the southern city group was significantly lower than that in the northern city group, but the growth rate was obviously higher than that in the north.

Although uncertainty exists in evaluating health losses due to the complexity and other factors, there is an improvement in inverting the space-time changes of AOD. Therefore, this research provides a theoretical basis 
for further research on haze pollution in China, as well as providing the basis for improving air quality management in the region. Meanwhile, this research can improve the understanding of the relationship between haze pollution and human health with urban expansion and economic growth in the world, and help to prevent global health disease caused by air pollution.

\section{Acknowledgements}

This research is founded by the National Natural Science Foundation of China (Nos. 71573250 and 41130750) and 135 Strategic Development Planning Project of Nanjing Institute of Geography and Limnology, CAS (No. 2012135006). Special thanks should go to Sarah Lindley, who has put considerable time and effort into her comments on the draft, as well as given some instructive advice and useful suggestions on this research.

\section{References}

1. CHENG H., GONG W., WANG Z., ZHANG F., WANG X., LV X., LIU, J., FU X., ZHANG G. Ionic composition of submicron particles $\left(\mathrm{PM}_{10}\right)$ during the long-lasting haze period in January 2013 in Wuhan, central China. Journal of Environmental Science. 26, 810, 2014a.

2. DU Z., HE K., CHENG Y., DUAN F., MA Y., LIU J., ZHANG X., ZHENG M., WEBER R. A yearlong study of water-soluble organic carbon in Beijing I: sources and its primary vs. secondary nature. Atmospheric Environment. 92, 514, 2014.

3. FU Q., ZHUANG G.,WANG J., XU C., HUANG K., LI J., HOU B., LU T., STREETS D.G. Mechanism of formation of the heaviest pollution episode ever recorded in the Yangtze River Delta, China. Atmospheric Environment. 42, 2023, 2008.

4. SHI Y., CHEN J., HU D., WANG L., YANG X., WANG $\mathrm{X}$. Airborne submicron particulate $\left(\mathrm{PM}_{1}\right)$ pollution in Shanghai, China: chemical variability, formation/dissociation of associated semi-volatile components and the impacts on visibility. Science of theTotal Environment. 473, 199, 2014.

5. SUN Y.L., ZHUANG G.S., TANG A.A. Chemical characteristics of $\mathrm{PM}_{2.5}$ and $\mathrm{PM}_{10}$ in Haze-Fog episodes in Beijing. Environmental Science and Technology, 40 (10), 3148, 2006.

6. KAUFMAN Y.J., FRASER R.S., FERRARE R.A. Satellite remote sensing of large scale air pollution. Geophysical Research, 95, 9895, 1990.

7. HUANG R., ZHANG Y., BOZZETTI C. High secondary aerosol contribution to particulate pollution during haze events in China. Nature, 514, 218, 2004.

8. ZHANG Y.J., TANG L.L., WANG Z. Insights into characteristics, sources, and evolution of submicron aerosols during harvest seasons in the Yangtze River delta region, China. Atmospheric Chemistry and Physics, 15, 1331, 2015.

9. GAO G. The climatic characteristics and change of haze days over China during 1996-2005. Acta Geographica Sinica, 63 (7), 761, 2008.
10. HUANG D.SH., XU J.H., ZHANG SH.Q. Valuing the health risks of particulate air pollution in the Pearl River Detal, China. Environmental Science \& Policy, 15, 38, 2012.

11. GUO J.P., WU Y.R., ZHANG X.Y. Estimation of $\mathrm{PM}_{25}$ over eastern China from modis aerosol optical depth using the back propagation neural network. Environmental science, 34 (3), 817, 2013.

12. SHEN G.F., YUAN S.Y., XIE Y.N. Ambient levels and temporal variations of $\mathrm{PM}_{2.5}$ and $\mathrm{PM}_{10}$ at a residential site in the mega-city, Nanjing, in the western Yangtze River delta, China. Journal of Environment Science and Health, 49 (2), 171, 2004.

13. ZHAI T.Y. Analysis of spatio-temporal variability of aerosol optical depth in the Yangtze River delta, China. East China Normal University, 2013.

14. LIU CH.C., MAO J.T., LIU Q.H. Study on the distribution and seasonal variation of aerosol optical depth in eastern China by MODI. Chinese Science Bulletin, 48 (19), 2094, 2003.

15. XU T.T., QING Y., GENG F.H. Seasonal variations in the vertical distribution of aerosols during dry haze periods in regions around Shanghai. Journal of Environment Science, 7 (33), 2165, 2012.

16. TONG Y.Q., YIN Y., QING L. Analysis of the characteristics of hazy phenomena in Nanjing area. China Environmental Science, 27 (5), 582, 2007.

17. FAN X.Q., SUN ZH.B. Analysis on Feature of haze weather in Xiamen city during 1953-2008.Transactions of Atmospheric, 32 (5), 604, 2009.

18. GAO M., QIU T.L., JIA R.ZH. Concentration and size distribution of bioaerosols at non-haze and haze days in Beijing. Environmental science, 12 (35), 4415, 2014.

19. YANG F., YANG L.X., MENG C.P. Seasonal variation and health-risk assessment of polycyclic aromatic hydrocarbons in $\mathrm{PM}_{2.5}$ in Jinan. Journal of University of Chinese Academy of Science, 3 (31), 389, 2014.

20. LIU J.F., DENISE L.M., LARRY W.H. Evaluating intercontinental transport of fine aerosols: Global health impact. Atmospheric Environment, 43, 4339-, 2009.

21. GREGORY R.C., BHUPESH A., SARIKA K. Asian Aerosols: Current and Year 2030 Distributions and Implications to Human Health and Regional Climate Change. Environmental Science Technology, 43, 5811, 2009.

22. HOU B., DAI L.ZH., WANG ZH. Time-series analysis of acute mortality effects of air pollution in Xi' an. Journal of Environment and Health, 12 (28), 1039, 2012.

23. YIN W.J., PENG X.W., SONG SH.ZH. Effect of atmospheric haze on cardiovascular disease of urban residents in Guangzhou: a time-series analysis [J]. Journal of Environment and Health, 12 (26), 1081, 2012.

24. MATUS K., NAM K.M., SELIN N.E. Health damages from air pollution in China. Global Environmental Change, 22 (1), 55, 2012.

25. ZHAO H.X., JIANG X.W. Evaluation of economic and industrial pollution gravity centers and the decoupling mechanism in Yangtze River delta. China Environmental Science, 33 (10), 1911, 2013.

26. YU X.N., LI X.M., DENG Z.R.D. Optical properties of aerosol during Haze-fog episodes in Beijing. Journal of Environment Science, 4 (33), 1057, 2012.

27. RAMANATHAN V., LI F., RAMANA M.V. Atmospheric brown clouds: Hemispherical and regional variations in long-range transport, absorption, and radiative forcing. Geophysical Research, 112, 1, 2007.

28. WU D. Hazy weather research in China in the last decade: a review. Acta Scientiae Circumstantiae, 32 (2), 257, 2012. 
29. TANG L.L., YU H.X., DING A.J. Regional contribution to $\mathrm{PM}_{1}$ pollution during winter haze in Yangtze River Delta, China. Science of the Total Environment, 541, 161, 2016.

30. QIAO T., ZHAO M.F., XIU G.L., YU J.Zh. Simultaneous monitoring and compositions analysis of $\mathrm{PM}_{1}$ and $\mathrm{PM}_{2.5}$ in Shanghai: Implications for characterization of haze pollution and source apportionment. Science of the Total Environment, 557, 386, 2016.

31. MAO J.T., LI CH.C. Observation and Study on the characteristics of aerosol radiation in 2005. Journal of Meteorology, 63 (5), 622, 2005.

32. KANG C.M., LEE H.S., KANG B.W. Chemical characteristics of acidic gas pollutants and $\mathrm{PM}_{2.5}$ species during hazy episodes in Seoul, South Korea. Atmospheric Environment, 38 (28), 4749, 2004.

33. MIN M., WANG P.C., ZONG X.M. Observation and study on aerosol properties in hazy days. Climatic and Environmental Research, 2 (14), 153, 2009.

34. CHEN X.L. Evaluating the health damage costs of atmospheric particulates. Xiamen University, 2008.

35. ZHANG M., SONG Y., CAI X. A health-based assessment of particulate air pollution in urban areas of Beijing in 2000-2004. Science of the Total Environment, 376, 100, 2007.
36. FAN CH.Q. Study on the correlation between aerosol optical depth and concentration of particulate matter 2.5 based on modis data - a case study of Ji'nan. Shandong University, 2014.

37. SHI J., CUI L.L., HE Q.SH., SUN L. The changes and causes of fog and haze days in eastern China. Acta Geographica Sinica, 65 (5), 533, 2010.

38. ZHAO M., QIAO T., HUANG Z. Comparison of ionic and carbonaceous compositions of $\mathrm{PM}_{2.5}$ in 2009 and 2012 in Shanghai, China. Science of the Total Environment, 536, 695, 2015.

39. ZHOU G., YANG F., GENG F. Measuring and modeling aerosol: relationship with haze events in Shanghai, China. Aerosol Air Quality Research, 14, 783, 2014.

40. MU Q., ZHANG SH.Q. An evaluation of the economic loss due to the heavy haze during January 2013 in China. China Environmental Science, 33 (11), 2087, 2013.

41. YU F., GUO X.M., ZHANG Y.Y. Assessment of health economic losses caused by air pollution in China in 2004. Journal of Environment and Health, 12 (24), 999, 2007.

42. LEWTAS J., WALSH D., WILLIAMS R. Air pollution exposure-DNA adduct dosimetry in humans and rodents: evidence for non-linearity at high doses. Mutation Research, $378(1 / 2), 51,1997$. 